and serious accidents by nearly one-half. ${ }^{10}$ A speed limit on some lengths of autobahn in West Germany reduced accidents by $30 \% .^{10}$ After the imposition of temporary speed limits at week-ends in Sweden it was concluded that accidents were fewer and less severe when they were applied than could have been expected if they had not been. ${ }^{13}$ Conversely, removing the 30 m.p.h. limit from some roads in Great Britain between 1945 and 1953 appears to have led to an increase in accidents causing injury, ${ }^{14}$ and raising the limit from 30 to 40 m.p.h. on some main roads near London in 1958 was followed by an increase in fatal and serious accidents. ${ }^{12}$

In the U.S.A. speed limits have long been an accepted means of promoting safer and orderly movement of traffic. There, nearly all roads, including those corresponding to our motorways, have speed limits ; in towns the limits are frequently as low as 20 m.p.h. and in oper country usually 65 m.p.h., though sometimes 60 or even 50 m.p.h. ${ }^{15}$ On the New York State Thruway, which has a speed limit of 65 m.p.h., the average speed of all vehicles in 1962 was 57.2 m.p.h. ${ }^{16}$; the average speed of vehicles on six British motorways (without a speed limit) in 1964 was 53.5 m.p.h. The average fatality rate on the major turnpike roads of U.S.A. in 1962 was 2.4 per 100 million miles travelled, ${ }^{16}$ while on the London-Birmingham motorway the corresponding rate in 1961-3 was 5.1 per 100 million miles travelled. ${ }^{17}$

More than 3,000 people were killed and over 100,000 injured on roads without a speed limit in Britain during 1964. The figures cited here suggest that the imposition-and enforcement-of speed limits on these roads would reduce the number of accidents and diminish the effects of collisions. They also support the Minister of Transport's evident intention of making more use of speed limits on roads. Permanent limits of 50 m.p.h. are now in operation on some 400 miles of rural main roads, and further lengths are to be restricted later. A 40 m.p.h. limit has been imposed on the elevated portion of M4 near Chiswick, and the question of speed limits for motorways in general is being considered. ${ }^{18}$ As in any other field of activity, no single measure will by itself prevent all accidents, but a limitation on the speed of vehicles appears at present to be an expedient which can bring about an appreciable reduction.

${ }^{1}$ Road Research Laboratory, Research on Road Safety, 1963, p. 479. H.M.S.O., London.

2 ibid., 1963, p. 378. H.M.S.O., London.

3 Ministry of Transport, Highway Code, H.M.S.O., London.

- Harris, A. J., Following Distances and the Probability of Danger of Collision between Vehicles, 1959. Road Research Laboratory, Research Note No. 3384. Unpublished.

${ }^{5}$ Newby, R. F., and Johnson, H. D., Traffic Engineering and Control, 1963, 4, 550.

- Ministry of Transport and Scottish Development Department, Road Accidents, I963, 1964. H.M.S.O., London.

'Moore, R. L.. in International Study Week in Traffic Engineering $I-6$ October, 1956, Stresa, Italy, 1956. World Touring and Automobile Organization, London.

8 Traffic Engineering and Control, 1962, 3, 685.

- Drew, G. C., Colquhoun, W. P., and Long, H. A., Brit. med. F., 1958, 2,993 .

${ }^{10}$ Smeed, R. J., Roads and Road Construction, 1960, 38, 393; 1961, 39, 15.

${ }_{11}$ Garwood, F., and Duff, J. T., Changes in accident frequency after changes in speed limits in the United Kingdom. Fifth International Study Week in Traffic Engineering, 26 September-1 October, 1960, Nice, France. Theme VI., 1960. World Touring and Automobile Organization, London.

13 Newby, R. F., Traffic Engineering and Control, 1963, 3, 678.

${ }^{13}$ Ministry of Communications, Stockholm. The Application of Temporary Road Speed Limits in Sweden, I96I-1962, 1965. Stockholm.

14 Garwood, F., Some Applications of Statistics in Road Safety Research, 1956. Manchester Statistical Society, Manchester.

${ }^{15}$ National Highway Users Conference, Inc., State Motor Vehicle Speed Limits, 1962. National Highway Users Conference, Inc., Washington, D.C.

New York.

${ }^{17}$ Department of Scientific and Industrial Research, Road Research, r963, 1964, p. 44. H.M.S.O., London.

${ }^{18}$ Hansard (Commons), i July 1964.

\section{Physiology of Lactation}

In a pamphlet ${ }^{1}$ published by the World Health Organization a Scientific Study Group summarize the present state of knowledge of the physiology of lactation. They make a well-justified plea for more research. There is no lack of facts on the various aspects of lactation in animals, as is obvious from a recent review of the knowledge in this field. $^{2}$ But even a superficial study of the literature shows that there are wide differences between species and that knowledge of lactation gained from experimental animals cannot be directly applied to man. Our knowledge of human lactation is sparse, and apart from the pioneer clinical studies of Waller and the work of Gunther, Hytten, and the Newtons few have devoted their attention to its problems.

In Great Britain to-day probably only a minority of mothers successfully establish lactation and continue to breastfeed their infants for any appreciable length of time. The reasons for the lack of enthusiasm in both the mothers and their attendants are complex. Social factors undoubtedly play a large part in determining this rejection of a natural function, a choice that is made easier because satisfactory artificial-milk substitutes are readily available. In a privileged community such as ours it is often difficult to find convincing arguments that will persuade the perplexed new mother to continue the struggle that is often required to establish lactation, especially when she is surrounded by others who suffer no discomfort and whose artificially fed infants seem to thrive equally well if not better than her own.

The main argument used in support of breast-feeding at present is that it favours the establishment of a satisfactory relationship between mother and child, one that is of lasting psychological benefit to both. Would it not be possible to produce convincing and tangible evidence in support of this argument ? The reflex release of oxytocin as a result of the suckling stimulus undoubtedly helps the involution of the genital organs. Moreover, the mothers of breast-fed infants seem to have less trouble with irregular bleeding and vaginal discharge in the puerperium, whereas the use of oestrogens for the suppression of lactation is often blamed for irregular bleeding, slow involution, and even later in life for an increased incidence of carcinoma of the breast. Surely we could replace such clinical impressions, some of which are no more than rumours, by acceptable proof ? Breast milk provides the infant with a certain amount of passive immunity. Is there no way of showing with certainty whether or not the human infant derives worth-while benefits when it is fed by its mother ?

In contrast the advantages of breast-feeding are still obvious in an underprivileged community, where the infant mortality rate from enteric diseases remains high. Further, where there is a lack of first-class protein the breast-fed infant is undoubtedly better off, because the protein content of the milk even of undernourished mothers is maintained at a normal level at the expense of the maternal tissues. In developing communities, therefore, there are two main problems associated with human lactation that need an urgent solution. What is the ideal diet for the nursing woman so that she can maintain adequate lactation without depriving herself ? And is it possible to improve the failing lactation of those mothers in whom the ability to breast-feed may make the difference between life and death for the child ?

\footnotetext{
Wld Hlih Org. techn. Rep. Ser., 1965, 305.

Milk: The Mammary Gland and its Secretions, ed. S. K. Kon and A. T. Cowie, 1961. London.
} 
Further research should bring a greater understanding of the processes at work in the initiation and maintenance of human lactation and help in the elucidation of related phenomena, as well as perhaps providing the immediate clinical benefit of galactagogues and more efficient ways of suppressing unwanted lactation. Pregnancy and lactation interrupt the normal cyclical activity of the hypothalamus and adenohypophysis, and during lactation this interruption apparently occurs in the absence of endocrine control from ovarian steroids. A study of the factors responsible for these normal changes and those causing abnormal lactation would increase our knowledge of gonadotrophic activity as a whole, thus leading to further progress in the control of fertility and the management of menstrual disturbances. It is to be hoped that the recent W.H.O. pamphlet may stimulate renewed interest in this unfashionable subject.

\section{Localized Myxoedema}

In 1840 von Basedow $^{1}$ described the condition that is now called pretibial myxoedema in a woman with exophthalmic goitre. Until 1942, however, when W. R. Trotter and K. C. Eden $^{2}$ published an important paper on this subject, little interest was taken in it except by dermatologists. Pretibial myxoedema has long been recognized to be associated with exophthalmos and thyrotoxicosis, past or present, but the gross finger clubbing reported in two patients by R. S. M. D. Inch and C. F. Rolland ${ }^{3}$ seemed at first to be an isolated finding. However, during the last decade a syndrome comprising hyperthyroidism, exophthalmos, localized myxoedema, finger clubbing, and hypertrophic osteoarthropathy (presenting in that order) has become recognized. In 1963 F. D. Malkinson found reports of 26 patients (including his own) with pretibial myxoedema and finger clubbing. ${ }^{4}$

Pretibial myxoedema is said to occur in about $3 \%$ of patients with toxic diffuse goitre. There may be vague aching in the legs, but more often the condition is discovered only on routine examination. It is doubtful whether localized myxoedema ever occurs in the absence of exophthalmos. The lesions first appear on the anterolateral aspect of the lower half of the legs: they later extend to the back of the legs, to the insteps, and sometimes as far as the knees. Extension of localized myxoedema to other sites is rare. In J. Sunseri's patient the legs and lower abdomen were affected, ${ }^{5}$ and $\mathrm{E}$. Lipman Cohen ${ }^{6}$ referred to a similar patient reported in 1900 by Achard. B. D. Cohen and his colleagues ${ }^{7}$ described two $^{2}$ patients with exophthalmic goitre and localized myxoedema affecting the arms as well as the legs, and in a survey of the literature they found that in 317 additional patients the arms were affected in only one. Pretibial myxoedema is usually

\footnotetext{
${ }^{1}$ Major, Ralph H., Classic Descriptions of Disease, p. 283, 3rd ed. 1945. Thomas, Springfield, Illinois.

Trotter, W. R., and Eden, K. C., Quart. F. Med., 1942, 11, 229

${ }^{8}$ Inch, R. S. M. D., and Rolland, C. F., Lancet, 1953, 2, 1239.

- Malkinson, F. D., Arch. Derm., 1963, 88, 303.

s Sunseri, J., ibid., 1943, 48, 70.

'Cohen, E. L., Brit. F. Derm., 1946, 58, 173.

'Cohen, B. D., Benua, R. S., and Rawson, R. W., Arch. intern. Med., 1963, 111, 641.

- Chremos, A. N., Amer. F. Med., 1965, 38, 954.

Chremos, A. N., Amer. F. Med., 1965, 38, 954.

10 Ludwig, A. W., Boas, N. F., and Soffer, L. J., Proc. Soc. exp. Biol. (N.Y.), 1950, 73, 137.

11 Gilliland, I. C., and Strudwick, J. I., Brit. med. F., 1956, 1, 378.

12 Querido, A., and Lameyer, L. D. F., Proc. roy. Soc. Med., 1956, 49, 209.
}

bilateral and the skin is raised in irregular firm swellings, the surface being dimpled and faint pink or brown or unaltered in colour. Coarse hairs may be seen over the swellings and local sweating may be a feature. In the course of years spontaneous disappearance of the lesions may occur. Recently an unusual example of localized myxoedema has been reported $^{8}$ in a male negro with the syndrome of thyrotoxicosis, exophthalmos, finger clubbing, and hypertrophic osteoarthropathy. The legs and the right hand were grossly myxoedematous, and surgical excision of masses from the hand with grafting was followed by the appearance of even larger masses. The deposits in this condition contain acid mucopolysaccharides-chondroitin sulphate and hyaluronic acid-combined in some form with proteins. The substance infiltrating the orbital contents is similar.

The common factor in the causation of exophthalmos and localized myxoedema has been thought to be overproduction of the thyroid-stimulating hormone (T.S.H.) of the anterior part of the pituitary gland in the absence of normal thyroid secretion. $^{910}$ I. C. Gilliland and J. I. Strudwick, ${ }^{11}$ however, found that, while thyrotoxicosis with severe proptosis is associated with a raised level of T.S.H. in the serum, a comparable rise is also found in cases of spontaneous myxoedema, in which proptosis does not occur. In thyrotoxicosis without severe exophthalmos the level of T.S.H. is not raised. They concluded that T.S.H. alone is not the cause of exophthalmos, but that some other factor, which may also be of pituitary origin, is involved. This view is supported by the work of A. Querido and L. D. F. Lameyer, ${ }^{12}$ who found no relation between the level of T.S.H. in the serum and exophthalmos, though the level was high in a patient with post-operative myxoederna, slight proptosis, and pretibial deposits.

Treatment of localized myxoedema has proved ineffective, though in one patient Malkinson ${ }^{4}$ found to his surprise that injections of T.S.H. into a lesion caused it to become flattened.

\section{Religion and Medicine}

In April 1962 the Archbishop of Canterbury held a meeting of interested persons on the subject of relationships between clergy and doctors. As a result of the recommendations of a working party then set up the Institute of Religion and Medicine was formally constituted in June $1964 .^{1}$ It has just produced its first Annual Report, and there its two major objects are set out: "To seek greater knowledge of the principles on which health in its widest spiritual, mental, and physical sense is based; and to promote a better understanding and co-operation between all people of whatever creed or discipline who are engaged in the fields of religion and medicine and related areas of human endeavour."

Various bodies, such as the Churches' Council of Healing, have been active for many years in this field, but the time seemed right for the formation of an open forum for discussion, with local field groups linked together by a central administration. There are already 400 members, about half ministers of religion and half members of the medical profession. Although the Institute is mainly Protestant Christian in its membership, Roman Catholics, Jews, and members of 